\title{
O Papel da Disseminação do Conhecimento de Interprojetos em Organizações Virtuais
}

The Role Of Inter-Projects Knowledge Dissemination In Virtual Organizations

\author{
Maysa Alves da Conceição Silva \\ Maria do Carmo Duarte Freitas
}

\section{Resumo}

Este artigo busca promover uma reflexão sobre o papel da disseminação do conhecimento em organizações virtuais, tendo como base as abordagens focadas em equipes de projetos. Estuda-se a relação dos temas sob a ótica da cooperação em interprojetos dentro das organizações virtuais. A principal contribuição desta pesquisa está na construção do conhecimento de uma organização e, consequentemente, na aprendizagem organizacional, o que é importante para o sucesso e alcance das metas e objetivos das organizações virtuais.

Palavras-chave: disseminação do conhecimento, interprojetos, gerenciamento de projetos, organizações virtuais

\begin{abstract}
In this paper reflects on the role of knowledge dissemination in virtual organisations, on the basis of the approaches that are highlighted in equips de projects. It studies the relationship of the themes from the perspective of cooperation in interprojects developed in virtual organizations. The main contribution of this research is the knowledge construction in an organization and thus to organizational learning, which is crucial to success and achievement of goals and objectives of virtual organizations.
\end{abstract}

Keywords: knowledge dissemination, inter-projects, project management, virtual organizations

\section{Introdução}

A economia do conhecimento tornou-se um recurso indispensável para as organizações. Silva et al. (2006) comenta o quanto é oportuna na tomada de decisão, se orientada para a produção e se utilizar métodos, instalações, máquinas, ferramentas e insumos que dependem do conhecimento neles embutidos.

Neste cenário, para se adaptar às mudanças, as empresas precisam ser capazes de aprender continuamente e, assim, atingirem maior capacidade inovativa e de obterem vantagens competitivas. Para que ocorra a aprendizagem organizacional, Nonaka e Takeuschi (1997) afirmam que é preciso ocorrer o processo de criação do conhecimento.

No inicio do ano 2000, a vantagem a ser oferecida pela organização era a qualidade, que dependia inteiramente das pessoas envolvidas e dos procedimentos usados para desenvolvê-los (PMI, 2004; NATALI et al., 2002). Com o passar dos anos, empresas que conseguem dominar o processo de criação do conhecimento podem vir a desenvolver produtos e serviços inovadores (NONAKA et al. apud HELGESEN, 2009), o que constitui uma vantagem competitiva.

As estruturas organizacionais baseadas em equipes ganham força, pois sua formação explora os potenciais intelectuais e de resolução de problemas dos recursos humanos e permite o compartilhamento de conhecimentos e experiências para atingir vantagem competitiva. Assim, despontam as equipes temporárias de projetos, as quais podem ser sobrepostas à estrutura funcional ou integradas ao projeto organizacional (GUERRINI et al., 2008).

A economia do conhecimento demanda novas estruturas organizacionais, orgânicas, flexíveis e aparentemente anárquicas, mas suficientemente coordenadas de forma a permitir que o conhecimento seja criado, armazenado, recuperado e reutilizado. Forças tecnológicas capacitantes, como o trabalho colaborativo e a interconexão de redes, permitem que empresas tenham um alto desempenho e tornem-se integradas e ampliadas (TAPSCOTT apud FREITAS JÚNIOR et al., 2001).

Dessa forma, as grandes empresas passam a se fragmentar em unidades de negócios, mais ágeis, autônomas e descentralizadas. Fato que ocorre devido ao uso intenso de tecnologia e das 
fronteiras digitais, que alteram o conceito de empresa e de trabalho, contexto este que recebeu o nome de organização virtual (KEEN apud FREITAS JÚNIOR et al., 2001).

Tendo em vista o exposto, este artigo analisa o papel da disseminação do conhecimento interprojetosnas organizações virtuais e sua importância para a construção da aprendizagem organizacional.

\section{Procedimentos metodológicos}

Realizou-se um estudo sobre o papel da disseminação do conhecimento em projetos de organizações virtuais. Busca-se entender as formas de transferência do conhecimento como uma das iniciativas de utilizar as estratégias de gestão do conhecimento nas empresas. Estas crescem no uso em larga escala, de intranets, softwares de mapeamento de processos, aplicações de Gerenciamento Estatístico de Dados, programas de colaboração e de integração de equipes de trabalho, sistemas para captação e sistemas de e-learning entre outras.

Daí a motivação para este trabalho, que começa na elaboração do referencial teórico em busca do entendimento sobre como ocorre a disseminação do conhecimento interprojetos em organizações virtuais $(\mathrm{OV})$ e é finalizado com a reflexão de um caso de sucesso relatado por Amato Neto no livro Inovação em serviços intensivos em conhecimento, de Roberto Bernardes e Tales Andreassi (2007, p. 303-324).

A opção metodológica é reforçada pelo interesse emergente no tema relacionado a interprojetos em organizações virtuais e a ausência ou carência de estudos sistematizados de caráter nacional.

\section{Disseminação do conhecimento interprojetos}

O emprego da disseminação do conhecimento justifica-se porque o principal foco do trabalho reside no ser humano e no estudo do ambiente corporativo. Detecta-se o surgimento de novos pressupostos nos processos e na vida da empresa que, afetada, muda os padrões comportamentais, culturais, políticos e as relações internas e externas de poder gerado pela posse do conhecimento.

Nonaka e Takeuchi (1997, p. 196) dividiram a organização em três níveis com atribuições diferentes, mas complementares e baseados no conceito de hipertextual (Figura 1).

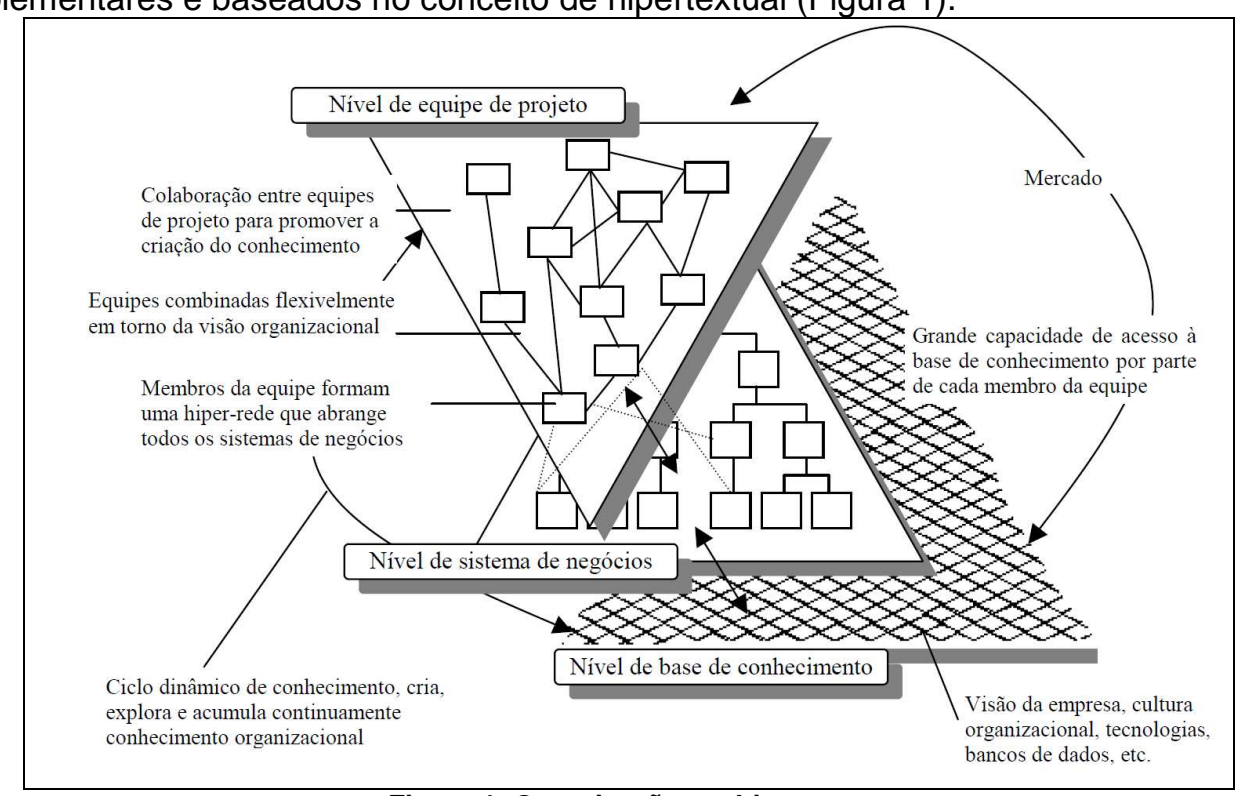

Figura 1: Organização em hipertexto

Fonte: Nonaka e Takeuchi, 1997, p. 196.

No nível de sistema de negócios, organiza-se como uma hierarquia tradicional; já o nível de equipe de projeto é organizado como uma força-tarefa típica. No nível base do conhecimento faz-se a categorização e contextualização do novo saber. A geração do conhecimento neste modelo é dinâmica e contínua na organização por apontar que o caminho para a construção do novo conhecimento acontece em espiral e apresenta quatro modos de conversão no qual cada volta finalizada caracteriza a efetiva produção do conhecimento, Figura 2. 


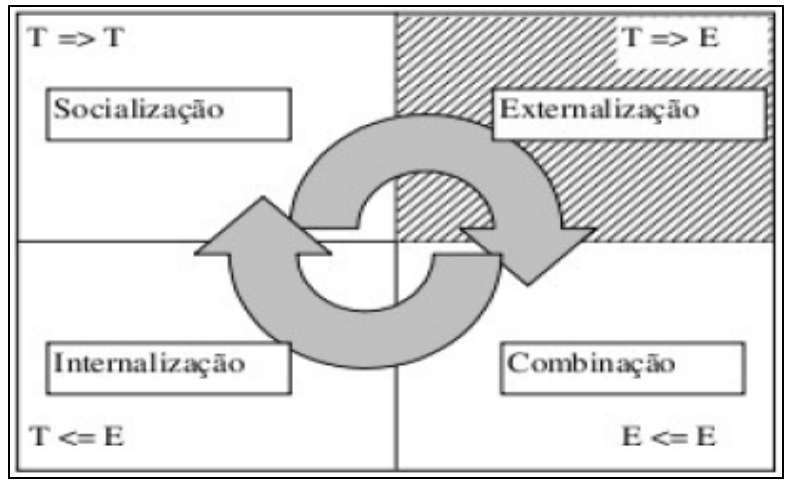

Figura 2: Espiral do conhecimento de

Fonte: Nonaka e Takeuschi apud Silva, 2006.

O Quadro 1 apresenta a definição com a exemplificação de como ocorre a conversão do conhecimento.

\begin{tabular}{|c|c|c|}
\hline $\begin{array}{c}\text { Modos de } \\
\text { conversão do } \\
\text { conhecimento }\end{array}$ & Definição & Exemplos \\
\hline Socialização & $\begin{array}{c}\text { Transformação de conhecimento tácito } \\
\text { para tácito }(\mathrm{T}=>\mathrm{T})\end{array}$ & $\begin{array}{c}\text { Seminários, treinamentos e } \\
\text { brainstorming ('tempestade de } \\
\text { idéias') }\end{array}$ \\
\hline Externalização & $\begin{array}{c}\text { O conhecimento tácito é convertido em } \\
\text { conhecimento explícito quando o } \\
\text { mesmo é registrado de maneira } \\
\text { assimilável por outras pessoas }(\mathrm{T}=>\mathrm{E})\end{array}$ & $\begin{array}{c}\text { Elaboração de um artigo } \\
\text { científico }\end{array}$ \\
\hline Combinação & $\begin{array}{c}\text { O conhecimento explícito, ao ser } \\
\text { comparado e combinado com outros } \\
\text { conhecimentos explícitos, pode ser } \\
\text { ampliado num processo de conversão } \\
\text { explícito para explícito (E => E) }\end{array}$ & $\begin{array}{c}\text { Elaboração da síntese de um } \\
\text { texto }\end{array}$ \\
\hline Internalização & $\begin{array}{c}\text { Quando internalizado por alguém, o } \\
\text { conhecimento explícito volta a ser } \\
\text { conhecimento tácito (E => T) }\end{array}$ & $\begin{array}{c}\text { Quando um leitor internaliza } \\
\text { as informações de um texto } \\
\text { através da leitura }\end{array}$ \\
\hline
\end{tabular}

Quadro 1: Modos de conversão do conhecimento

Fonte: elaborada pelas autoras

Uma forma de alcançar a aprendizagem organizacional é a utilização de estruturas baseadas em equipes de projetos, já que estes podem gerar novos conhecimentos para o ambiente empresarial, por meio da utilização de técnicas de gerenciamento de projetos (GP). No Guia PMBOK (PMI, 2004), o GP é descrito como a aplicação de conhecimento, habilidades, ferramentas e técnicas às atividades do projeto, a fim de atender aos seus requisitos. Para DELAIDE (2007), o GP é a aplicação de conceitos, ferramentas e técnicas para a realização de projetos dentro do prazo e do orçamento, ao mesmo tempo em que atende às necessidades do cliente, ou seja, com procedimentos específicos de planejamento, garantia e controle da qualidade.

Freqüentemente, porém, tais projetos deixam de aproveitar experiências anteriores, por motivos diversificados. Brookes e Leseure (2008) citam, por exemplo, as estruturas organizacionais temporárias, grupo heterogêneo de pessoas e competição por recursos. Este problema resulta na ocorrência de erros já contornados no passado, e no retrabalho, ou seja, no desenvolvimento de soluções reinventadas durante o ciclo de vida do projeto.

Por este motivo, torna-se necessária a adoção de práticas que proporcionem a troca de lições aprendidas intra e interprojetos, garantindo a disseminação do conhecimento. Desta forma, o gerenciamento de projetos contribui para o aumento da aprendizagem organizacional, visto que novos conhecimentos serão gerados para organização no decorrer do processo.

A competitividade empresarial mostra-se com fatores de natureza tangível (equipamento de produção, mão-de-obra pouco qualificada e custos dos materiais), e surgem outros fatores de competitividade essencialmente intangíveis - o conhecimento como fonte de vantagem competitiva é cada vez mais importante.

Na denominada "velha economia" as grandes empresas detinham o segredo do sucesso, porém as variáveis chaves para o sucesso são a inovação, a agilidade e a aprendizagem, que se manifestam em redes e reúnem pequenas empresas com capacidade de gerir seu conhecimento.

Essa organização nova assume inúmeras denominações e definições, mas, ágil, reúne sua equipe em rede distribuída que atua como consumidores e clientes de si mesmos. 


\title{
Organizações virtuais
}

Hill apud Balceiro et al. (2002) define a organização virtual como:

\begin{abstract}
Uma aliança dinâmica de pessoas ou organizações que compõem o grupo, contribuindo com competências complementares e com recursos, utilizando as TICs (Tecnologias de Informação e Comunicação) intensamente o que, muitas vezes, reduz a necessidade de estarem presentes fisicamente, apesar de se colocarem coletivamente disponíveis umas para as outras. A meta do grupo é realizar negócios ou trabalhar colaborativamente de forma a atingir objetivos comuns, oferecendo um produto ou serviço para o mercado como se fosse uma só empresa, exigindo um grande esforço de coordenação e gerenciamento.
\end{abstract}

Este tipo de organização virtual apresenta características especificas, que Jagers et al. (apud FREITAS JÚNIOR et al., 2001) destacam, entre as principais:

\footnotetext{
- Dispersão geográfica: as empresas geralmente não estão próximas umas das outras; - Competências essenciais complementares: as empresas participantes se complementam, contribuindo na sua área de competência;

- Comunicação e tecnologia da informação: a existência da OV está vinculada às TICs;

- Participantes em mudanças: a OV pode ser composta por diferentes empresas a cada dia, de acordo com novas necessidades e oportunidades de negócios.
}

Uma OV é independente de sua estrutura organizacional, já que cada nó da rede tem sua própria estrutura, que pode ser modificada sem interferir nos demais outros nós (JOIA apud FREITAS JÚNIOR et al., 2001), Figura 3.

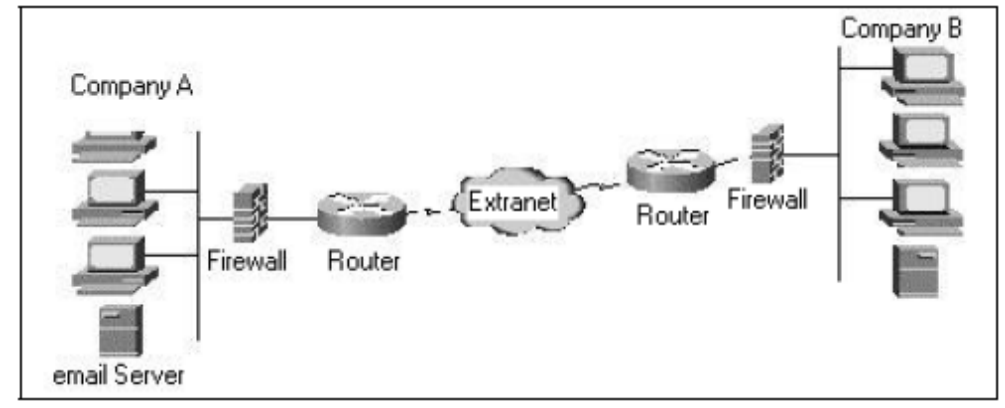

Figura 3: Visão geral de uma organização virtual

Fonte: JOIA apud FREITAS JÚNIOR et al., 2001

Esse tipo de organização virtual necessita da existência da figura do integrador (Virtual Broker), que mantém as competências relativas ao negócio, terceirizando a maioria dos demais processos produtivos. Além disso, é responsável por gerenciar as restrições e dependências entre os demais parceiros comerciais, coordenando as transações efetuadas (FREITAS JÚNIOR et al., 2001). Para Freitas (2003), o Broker é o componente regulador das atividades assumidas por cada empresa parceira.

Bernardes et al. (2007) conceituam as OV como redes dinâmicas de cooperações entre empresas, instituições e outros tipos de organizações. Estas redes, pela maior utilização das tecnologias da telemática (Internet, por exemplo), buscam "potencializar a competitividade dos parceiros integrantes da rede e visualizar a exploração de novas oportunidades de negócios do mercado global".

Para Bernardes et al. (2007), há razões estratégicas para a adoção do modelo de organizações virtuais para alcançar maior competitividade no mercado. Dentre elas, destacam-se: compartilhamento de recursos, instalações e competências, a fim de ampliar o alcance geográfico ou tamanho aparente que um concorrente pode oferecer a um cliente; e divisão de riscos e custos de infra-estrutura para candidatar-se à concorrência. Este entendimento completa-se com a visão sobre o ciclo de vida destas organizações.

\section{Ciclo de vida de uma Organização Virtual}

A importância do ciclo de vida na organização originou diferentes visões entre os pesquisadores; este trabalho destaca três modelos. 
O Ciclo de vida de acordo com FUCHS é composto por cinco fases, conforme segue (TRÖGER et al., 1998):

1. Pré-fase: analisa oportunidades e pressões, bem como competências e recursos necessários e disponíveis. Com base nessa análise, é decidido se a organização deve permanecer só, adquirir ou fundir-se a outra companhia ou cooperar com parceiros;

2. Configuração: a configuração é a fase onde a OV é constituída;

3. Projeto: a fase de projeto deve implementar os objetivos e roteiros formulados em padrões que são derivados dos objetivos da OV. Esses roteiros determinam a aplicação dos processos de referência, TICs, logísticas e aspectos culturais;

4. Operação: a fase de operação é a real fase de geração de valores da OV;

5. Dissolução: a dissolução pode ocorrer na forma do final da sua existência, quando todas as relações entre os parceiros são desfeitas, não significando que os parceiros param as atividades entre eles.

A Figura 4 ilustra as cinco fases do ciclo de vida elaborado por FUCHS.

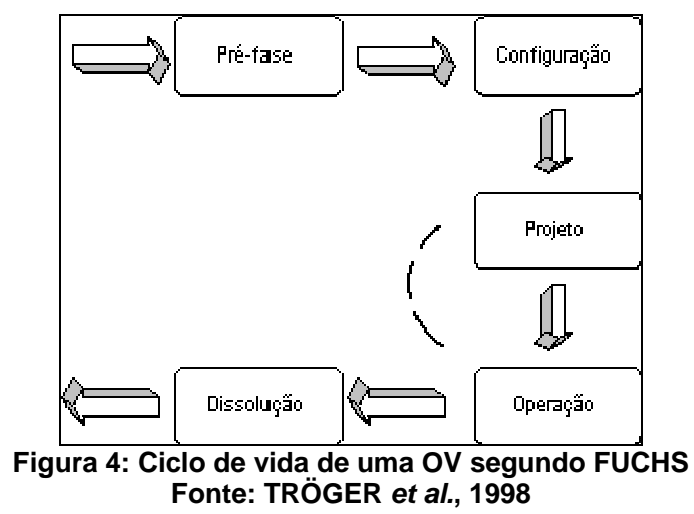

Para Merkle, o ciclo de vida é composto por quatro fases, que são as seguintes (TRÖGER et al., 1998), conforme ilustra a Figura 5.

1. Preparação e análise: análise dos processos intraorganizacionais. Define-se o perfil dos parceiros necessários;

2. Configuração: a fase de configuração consiste no "nascimento" da rede cooperativa. Com base no perfil dos parceiros, definido na fase de preparação, os parceiros para a cooperação são procurados:

3. (Re) Projeto: Nessa fase, a infraestrutura - de processos e de informação - da OV deve ser implementada;

4. Operação: podem ser usadas técnicas clássicas de qualidade a fim de assegurar a qualidade dos processos. A operação das redes de cooperação é alterada se uma companhia não puder suportar os padrões de qualidade da rede.

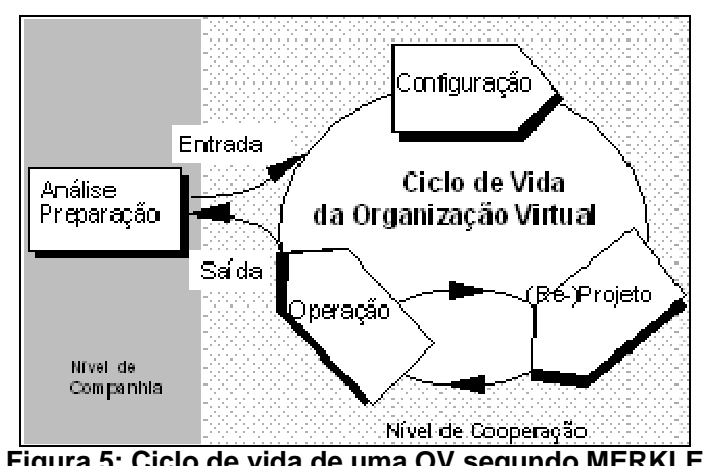

Figura 5: Ciclo de vida de uma OV segundo MERKLE

Fonte: TRÖGER et al., 1998

O ciclo de vida segundo BREMER e CORRÊA é composto por seis fases (Figura 6). 


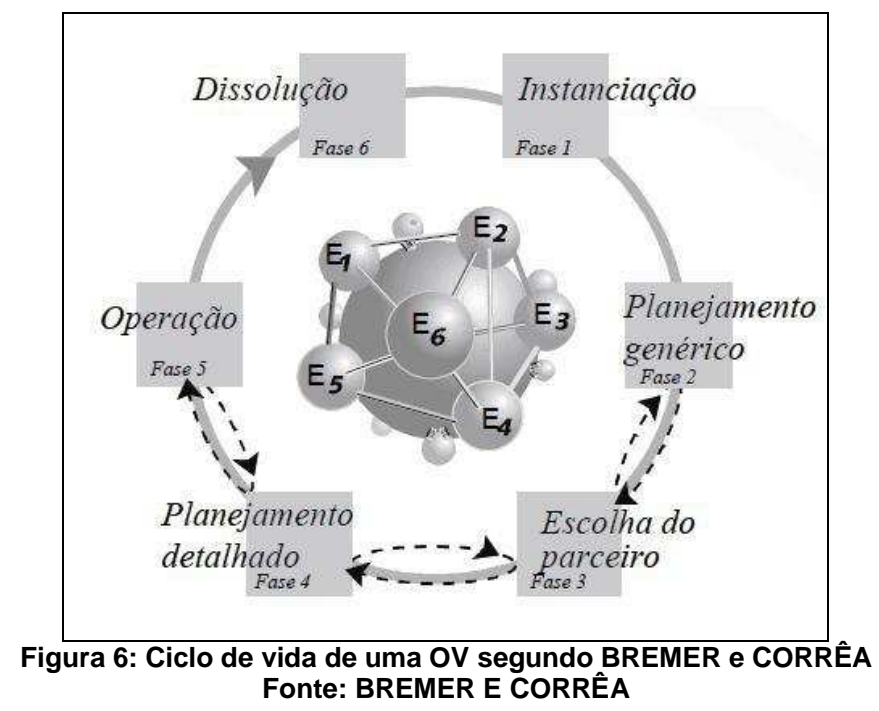

A instanciação de uma OV pode ocorrer nas variantes: reativa, que corresponde a requisições de ofertas por parte de clientes em produtos ou serviços que são divulgados pela OV, e proativa, que satisfaz aos resultados do processo de elaboração de visões estratégicas, realizado por grupos específicos para essa finalidade.

O planejamento genérico utiliza-se de modelos de referência de projetos anteriores como ponto de saída para implementar o novo. Diferentes cenários com modelos organizacionais e de operação genéricos podem ser gerados e comparados para compatibilizar com a oportunidade.

A seleção de parceiros é feita com base nas informações resultantes da fase anterior. Cada parceiro interessado deve apresentar propostas de participação, fornecendo seus dados sobre custo e tempo. Além disso, a conformação com estrutura organizacional da OV, a capacidade dos recursos próprios e a forma de utilização da tecnologia de informação é analisada.

No planejamento detalhado, os modelos ou produtos trabalhados são adaptados à situação vigente de cada parceiro escolhido. Os fluxos de informações e de materiais são também detalhados e aprovados por todos. É o momento da definição de responsabilidade legal e direito de utilização.

A operação é iniciada com base nos detalhamentos realizados na fase anterior. As ordens de pedido são executadas e cada parceiro exerce sua competência. Para tal finalidade, diferentes tecnologias podem ser utilizadas como sistemas de workflow, em que os documentos que pertencem ao fluxo de informação são transmitidos eletronicamente. Conforme o nível de confiança entre os parceiros, pode haver integração de sistemas e de banco de dados, mediante uma modelagem mais detalhada em termos de especificação dos aplicativos utilizados. O processo de monitoramento é implantado nesta fase e tem como base a freqüente análise do sistema de desempenho, que é alimentado com dados da atuação conjunta dos parceiros.

A dissolução da OV acontece quando determinados índices de desempenho, previstos no plano de dissolução elaborados no planejamento detalhado, são atingidos. Na decisão de dissolução, ocorre o armazenamento de informações (modelos, índices, parceiros) para uso futuro e distribuição dos direitos adquiridos.

Enfim, o ciclo de vida das OV considera ainda uma série de variáveis, dentre elas: mercado, objetivo, recursos, definição de responsabilidades e legalização da organização.

\section{Dificuldades na implementação de uma OV}

A seguir as principais características das OV, segundo Tröger et al., (1998):

compartilham a infra-estrutura, riscos e desenvolvimento de pesquisa, juntamente com os custos de recursos humanos e tecnológicos;

aproveitam rapidamente as oportunidades, devido à maior facilidade de configuração;

estruturam-se de modo ágil e podem não possuir nenhum centro;

aproveitam competências centrais e complementares e desta forma conseguem atingir a excelência;

aumentam as facilidades e tamanho percebido (uma companhia pequena pode usar uma organização virtual para aumentar as suas capacidades e permitir-se competir para oportunidades maiores que ela poderia, de outra forma, perder.); 
ganham acesso a novos mercados e compartilham o mercado;

requerem o uso de todo o potencial da tecnologia;

baseiam-se na confiança e na interdependência entre os parceiros;

não possuem fronteiras rígidas como as organizações tradicionais;

têm um caráter transitório, ou seja, duram enquanto dura o objetivo que as originou;

possuem uma hierarquia pouco estruturada e de natureza também transitória;

são independentes das empresas que as compõe. são:

Freitas (2003) detalha que os principais problemas encontrados na implementação de uma OV

- Comunicação: as comunicações globais podem não ser suficientes para todas as corporações virtuais;

- Compatibilidade de equipamentos de comunicação: a rotatividade de parceiros aumenta as despesas, pois os parceiros encontram-se geograficamente distribuídos e muitas vezes não dispõem de condições de aquisição ou trocas diferenciadas, nas configurações de padrões computacionais;

- Restrições ou indefinições legais: questões como divisão de responsabilidades e contratuais podem se tornar um obstáculo;

- Adaptação dos indivíduos ao novo ambiente: a ausência humana (fisicamente) faz com que os trabalhadores tenham que se acostumar com o isolamento;

- Cultura empresarial: resistência dos indivíduos em compartilhar conhecimento.

Para Amato Neto (2005 apud Bernardes et al., 2007), as principais barreiras relacionadas ao novo ambiente de trabalho é a resistência às mudanças nos procedimentos de trabalho e das práticas administrativas. Além destes, segundo o autor, há restrições quanto à questão da segurança da informação veiculada, e, em menor grau, dificuldades de comunicação (falhas na infra-estrutura).

\section{A disseminação do conhecimento interprojetos em organizações virtuais}

Para Bernardes et al. (2007), o sucesso da configuração organizacional de redes virtuais depende do fluxo contínuo de conhecimentos para reduzir custos e maximizar benefícios e ganhos coletivos. Para atingi-los, uma efetiva coordenação dessa rede deve gerar e compartilhar conhecimentos necessários.

Existem dois fatores que determinam a geração, adoção e difusão do conhecimento em determinada cadeia produtiva, o primeiro trata de regulamentar a integração entre a empresa central (hub-firm) e suas subsidiárias, afim de facilitar o processo de inovação e difusão nas subsidiárias da rede e o segundo discute o esforços diferenciados na comunicação inter e intraunidades (Ghoshal e Ballet apud Bernardes et al., 2007).

Ainda segundo o autor, tais fatores evidenciam a importância da disseminação do conhecimento a fim de promover a inovação em organizações complexas.

Nesta configuração de redes de empresas, cada membro tem acesso aos recursos existentes em toda a rede. O risco de cada empreendimento, especialmente no caso de grandes projetos, é dividido entre os parceiros da rede (BERNARDES et al., 2007).

Para Balceiro et al. (2002), as organizações que estão em constante aprendizado são consideradas ideais para integrar uma rede. Desta maneira, previnem-se eventuais surpresas e mantêm-se uma fonte de informações sobre os membros da rede, que suporta as decisões exigidas no momento da escolha das oportunidades de negócio a serem atendidas.

Neste contexto, a abordagem organizacional baseada em projetos pode ser importante para as empresas que fazem parte de uma rede virtual, visto que os projetos são intensivos em conhecimento. A disseminação de conhecimentos durante a execução de projetos enriquece não somente os resultados esperados, mas também oferece à organização possibilidades ampliadas de desenvolvimento de novas soluções a partir da inovação e do aprendizado contínuos, favorecendo seu crescimento auto-sustentado e flexível (GATTONI, 2003).

\section{Institute for Techonology Management: Reflexão de um Caso de Sucesso:}

Instituto criado a partir da colaboração de empresas e instituições da Suíça, que gerencia uma rede virtual de cooperação de empresas no formato de fábrica virtual. Conta com o apoio e suporte 
financeiro de grandes empresas transacionais, tais como, Daimler-Benz@ , Hewlett-Packard@ e Philips@. Uma das principais atividades do Instituto resultou na integração tecnológica de indústrias que fomentou o crescimento de empreendimentos e quadriplicou o número de empresas da região (AMATO NETO, 2007).

A criação desta rede surgiu da exigência cada vez maior do mercado por flexibilidade e baixo tempo de resposta às excessivas flutuações de demanda. Para o autor, as empresas se reuniram em busca de uma redução de custos dos produtos pela formação da rede, comparando-se com o seu isolamento. A redução resulta na melhoria do processo de especialização de cada fábrica.

Destaque às peculiaridades que induziram a se firmar o acordo: de exigência cada vez maior do mercado por flexibilidade e menor tempo de resposta às excessivas flutuações de demanda; reconhecimento das competências características na especialização de cada empresa - tornou o empreendimento rentável. O modelo de negocio parte de uma demanda especifica de uma grande organização e as empresas cooperadas se reúnem e decidem quem tem competência para cada etapa do processo - design, fresamento, tratamento e etc - elege-se um broker que cuidará de gerência os conflitos e captação de novos parceiros.

Fato que se evidencia pelo crescente compartilhamento de serviços, de caráter mais tecnológico. Para Schulman (apud Bernardes et al., 2007), a adoção dessa estratégia reflete numa série de benefícios, conforme segue:

\footnotetext{
- Serviços compartilhados reduzem custos e acrescentam valor à empresa;

- Agiliza os negócios e propicia crescimento estratégico;

- Cria uma nova responsabilidade de gerenciamento;

- Permite que várias Unidades Estratégicas de Negócios (UEN's) de uma grande corporação foquem na melhoria contínua de suas operações e em seus processos-chave (core competences);

- Fornece concentração de recursos;

- Fornece atividade de suporte a baixo custo e com elevados níveis de qualidade;

- Viabiliza maior alavancagem tecnológica por parte das empresas.
}

Estes elementos estão presentes no relato e conduzem a refletir em quais os impedimentos que enfrentam as empresas brasileiras na criação destas redes virtuais. Pesquisas anteriores já comprovavam estes aspectos.

Troger et al. (1998), quando apresentam as características das Organizações Virtuais, destacavam o uso da tecnologia como provedor de suporte na comunicação eletrônica de dados e nas demais tecnologias relacionadas; o core competence como uma excelência, em que cada parceiro se coloca e contribui por meio do que sabe fazer de melhor, sendo que vale o sentido de oportunidade, fundamental para a realização dos negócios e das parcerias virtuais. Destaca-se ainda que não existe fronteira nem cultura que atrapalhe a relação de confiança e a confiabilidade recíprocas, que dão sentido e corpo ao lastro técnico e gerencial reunido entre parceiros e clientes.

O crescimento do setor de serviços na economia mundial tem em seu processo de geração e disseminação do conhecimento um dos aspectos mais relevantes para as empresas alcançarem vantagens competitivas de mercado.

Nesse contexto, com o intuito de alcançar maior poder de competitividade, as empresas devem se apoiar cada vez mais na criação de organizações virtuais. O compartilhamento de serviços entre as empresas de uma OV traz benefícios não só para elas, mas também para a OV como um todo.

A abordagem organizacional baseada em projetos possui papel fundamental para as empresas integrantes de uma OV, visto que por meio do compartilhamento do conhecimento gerado nos projetos, as empresas poderão inovar mais e reutilizar conhecimentos anteriores. A disseminação de conhecimentos interprojetos de uma OV pode gerar o aprendizado contínuo das organizações, que aumentará a capacidade da empresa em responder mais rapidamente as demandas do mercado, favorecendo a aquisição de vantagens competitivas e contribuindo para a sua subsistência frente à concorrência global.

A disseminação do conhecimento no âmbito do interprojetos em organizações virtuais é visto sob a ótica da gestão da informação, que requer foco na forma que ocorre a comunicação e seus inúmeros desafios. Os problemas passam pela perda de controle por falta de técnicas de uso múltiplos nas corporações e dos diferentes modelos de gestão e entendimento de uma mesma técnica.

As empresas que em rede formam uma OVs são independentes, o que gera controles de segurança insuficiente e falta de interoperabilidade entre os sistemas utilizados por razões semânticas, de código ou de tecnologias não familiares.

A convivência com riscos de expansão, a concorrência e obsolescência naturais e permanentes, próximos e rápidos são uma preocupação constante na vida da OV. Logo, todos estes fatos pedem fazer as comunicações mais eficientes para que possam atravessar estas barreiras. 


\section{Considerações finais}

As OV surgem num mundo de constantes mudanças, onde o mercado e a concorrência são globais. As empresas precisam adquirir mais capacidade inovativa e, consequentemente, mais vantagens para competir globalmente.

Para atingir esse objetivo, as empresas que compõem uma rede virtual precisam estar em processo de constante aprendizado. Assim sendo, a disseminação de conhecimento torna-se essencial no âmbito das organizações que fazem parte dessa rede.

Os maiores desafios e barreiras a serem transpostos para a efetiva viabilização das organizações virtuais passam pela mudança de cultura, identificação das expectativas, conhecimento das relações e do comportamento entre as pessoas (profissionais e clientes) e seus diferentes padrões vigentes em cada organização participante. Sem esquecer que cada empresa é composta por indivíduos e de como ajudá-los a adaptar-se ao novo ambiente.

Uma forma de aumentar o aprendizado da rede virtual é a adoção do gerenciamento de projetos em OV, que permitirá com que novas iniciativas organizacionais possam ser tomadas com aproveitamento parcial ou total das experiências já vividas por empresas parceiras. Estas experiências podem ser originadas de projetos já concluídos ou ainda em andamento.

Enfim, a disseminação do conhecimento interprojetos coopera no sentido de fomentar o aproveitamento máximo da criação e disseminação do conhecimento organizacional entre os componentes de uma rede virtual e, assim, contribuir para que a OV alcance suas metas e objetivos.

\section{Agradecimentos}

Agradecimentos à Fundação de Amparo à Pesquisa do Estado do Amazonas - FAPEAM e a todas as pessoas que colaboraram direta ou indiretamente para a realização deste trabalho.

\section{Referências}

AMATO NETO, J. Redes Virtuais de Pesquisa e inovação em serviços. In: BERNARDES, R.; ANDREASSI, T.. Inovação em serviços intensivos em conhecimento. São Paulo: Ed. Saraiva, 2007, cap. 12.

BALCEIRO, R. B.; FIGUEIREDO, P. P.. A gestão de competências nas organizações virtuais: o caso da empresa UR2. In: Workshop Brasileiro de Inteligência Competitiva e Gestão do Conhecimento, 3., 2002, São Paulo. Anais. In: Congresso Anual da Sociedade Brasileira de Gestão do Conhecimento, 1., 2002, São Paulo. Anais.

BERNARDES, R.; ANDREASSI, T.. Inovação em serviços intensivos em conhecimento. São Paulo: Ed. Saraiva, 2007.

BROOKES, N. J.. LESEURE, M.. A gestão do conhecimento interprojetos. Mundo PM: Editora Mundo. Ediçao 20, abril de 2008.

DELAIDE, K.. The role of project management in knowledge management. Earticles. info, 2007. Disponível em <http://earticles.info/>, acesso em 05 de setembro de 2009.

FREITAS JÚNIOR, O. G.; PACHECO, R. C. S.; TAIT, T. F. C.. O conceito de inteligência para uma organização virtual. In: XXI Encontro Nacional de Engenharia de Produção (ENEGEP), Salvador, 2001.

FREITAS, M. C. D. Educação Corporativa: um método de apoio à decisão para implantação nas Organizações Empresariais. Florianópolis, PPGEP/UFSC, 2003. Tese de Doutorado (Doutorado em Engenharia de Produção) - Programa de Pós-graduação em Engenharia de Produção, Universidade Federal de Santa Catarina, Florianópolis.

GATTONI, R. L. C.. A gestão do conhecimento aplicada à prática de gerência de projetos. In: $4^{\circ}$ Congresso Iberoamericano de Gerência de Projetos, Rio de Janeiro, 2003. Disponível em <http://www.pmisp.org.br/congresso/>, acesso em dezembro de 2009. 
GUERRINI, F. M.; ESCRIVÃO FILHO, E.. Gestão e Organização na era da informação. São Carlos: SEP_EESC_USP, 1a. Edição, 2008. Cap. 4.

HELGESEN, S.. A sabedoria de Ikujiro Nonaka. Revista HSM Management, seção alta gerência, n. 75 , a. 13 , v. $4,2009$.

NATALI, A. C. C.; FALBO, R. A. Knowledge management in software engineering environments. Computer Science Department, Federal University of Espírito Santo, Vitória/ES, Brasil, 2002.

NONAKA, I.; TAKEUCHI, $H$. Criação de conhecimento na empresa: como as empresas japonesas geram a dinâmica da inovação. 14. ed. Rio de Janeiro: editora Campus, 1997.

PMI - PROJECT MANAGEMENT INSTITUTE INC.. Um guia do conjunto de conhecimentos em gerenciamento de projetos. Pennsylvania, EUA, 3. ed., 2004.

SILVA, F. A. C.; ESPÍNOLA, M. J. C.; VILAR, R. M.. Gestão do conhecimento e inteligência competitiva: desafios para as organizações produtivas. Inf. \& Soc.: Est., João Pessoa, v.16, n.1, 2006, p.119-131.

TRÖGER, A.; OLIVEIRA, J. P. M.. Um Modelo de Ciclo de Vida para Organizações Virtuais. Disponível em < http://palazzo.pro.br/artigos/EM-01/index.htm>, acesso em março de 2010. 